\title{
COVID-19: Transport Operation from an Endemic Area
}

\author{
(1) İshak Șan ${ }^{1}$, (1) Semih Korkut ${ }^{2}$, (1) Eren Usul ${ }^{3}$, (1) Burak Bekgöz ${ }^{4}$, (1) Afșin Emre Kayıpmaz ${ }^{4}$ \\ 1Department of Emergency Medicine, University of Health Sciences Turkey, Ankara City Hospital, Ankara, Turkey \\ 2Department of Emergency Medicine, University of Health Sciences Turkey, Kartal Training and Research Hospital, İstanbul, Turkey \\ ${ }^{3}$ Clinic of Emergency Medicine, Sincan State Hospital, Ankara, Turkey \\ ${ }^{4}$ Clinic of Emergency Medicine, Ankara City Hospital, Ankara, Turkey
}

\begin{abstract}
Aim: Turkish Government launched an operation to transport the Turks living in Wuhan, China to Turkey because of coronavirus disease-19 (COVID-19) pandemia. In this study, the transport method, medical measures taken and quarantine process were evaluated.

Materials and Methods: Turkish citizens living in China had reported to the Turkish Embassy in Beijing that they wanted to return to Turkey. Thereupon Turkish Embassy in Beijing contacted the Ministry of Foreign Affairs of Turkey, and it was decided to transport Turkish citizens from China to Turkey. The governments of Georgia, Bulgaria, Azerbaijan, and Albania, who were aware of this development, requested the Ministry of Foreign Affairs of Turkey for their own citizens to be included in this transport.

Results: A total of 42 people were transported from city Wuhan to Turkey. Among them, 27 were citizen of Turkey, 6 were citizens of Azerbaijan, 4 were dual citizens of China and Turkey, 3 were citizens of Georgia, 1 was citizen of Bulgaria and 1 was citizen of Albania.

Conclusion: It suggests that there is a serious outbreak, as COVID-19 disease transmits from human-to-human and spread rapidly worldwide. Therefore, taking this outbreak seriously and taking all necessary measures will reduce the spread of COVID-19.

Keywords: COVID-19, patient transport, prehospital
\end{abstract}

\section{Introduction}

On December 31 2019 , the World Health Organization (WHO) China Country Office was informed of cases of pneumonia of unknown etiology detected in the city of Wuhan in Hubei Province, China. The Chinese authorities identified a new type of coronavirus (2019-nCoV), which was isolated on January $7^{\text {th }}$ 2020. The disease then began to appear outside of China (Thailand, Japan, and Korea, respectively) (1). The WHO agreed that the outbreak met the criteria for a Public Health Emergency of International Concern (PHEIC) on January 30 2020 (2). On February $11^{\text {th }} 2020$, the WHO named the disease COVID-19, short for "coronavirus disease 2019" (3). By March 11 $1^{\text {th }} 2020$, a total of 4,290 patients had died in 113 countries (4).

COVID-19 spread rapidly in China and was soon seen in other countries (5). It was also confirmed that the disease was being transmitted from humans to humans (6). The Chinese government took some measures to control the outbreak. On January $23^{\text {rd }}$ 2020 , the government quarantined the city of Wuhan. Many cities in China have closed their public transportation systems (5). Later, the United States government canceled all flights from China (7). Turkey stopped all flights arriving from China until the end of January.

With the COVID-19 pandemic, aircraft and helicopter ambulances, as well as land ambulances, have had to deal with COVID-19 patients, a situation that they had not experienced before. There were no established guidelines on COVID-19 patient transport and information on this subject is still limited. In addition, it is known that aeromedical crew members are at higher risk than hospital staff (8).

The Turkish government launched an operation to transport the Turks living in Wuhan, China, back to Turkey. In this study, 
the transport method, the applied medical measures, and the quarantine process are evaluated.

\section{Materials and Methods}

Turkish citizens living in China had reported to the Turkish Embassy in Beijing that they wanted to return to Turkey. The Turkish Embassy in Beijing then contacted the Ministry of Foreign Affairs of Turkey, and it was decided to transport Turkish citizens from China to Turkey. The governments of Georgia, Bulgaria, Azerbaijan, and Albania, who were aware of this development, requested that the Ministry of Foreign Affairs of Turkey also include their own citizens in this transport, a request that the Turkish government accepted.

To transfer Turks and their Chinese spouses to Turkey, an Airbus A400M cargo aircraft of the Turkish Armed Forces was adapted for passenger transfer. A total of 75 passenger seats were mounted on this plane. In addition, the necessary materials were placed in the back of the aircraft (Table 1). For this operation, a total of 19 personnel, including four pilots, six crew members, two doctors (infectious disease specialists), one paramedic, three nurses, two press members, and one Foreign Ministry staff member were assigned. The Science Board of the Ministry of Health of Turkey decided to keep the passengers, medical staff, and aircraft crew under quarantine for 14 days after transport. A hospital building that was recently closed for service and was empty at that time was used for the quarantine. All of the medical equipment of that hospital was reviewed, all necessary medicines and medical supplies were provided, and doctors and nurses were assigned for patient follow-up. It was decided to transfer the passengers from the airport to this hospital by land ambulances. For this transfer, 10 ambulances and seven multi-stretcher ambulances (capable of transferring four patients at once) were prepared.

The plane took off from Ankara Etimesgut Military Airport on January $31^{\text {st }}, 2020$ at 08:30 a.m. to fly to Wuhan. The flight lasted 16 hours and 30 minutes (with 1 hour and 30 minutes for refueling at Ulaanbaatar Cengiz Han Airport in Mongolia). The plane landed at Wuhan Tianhe International Airport (WUH) airport on February 1 ${ }^{\text {st }}, 2020$ at 00:48 p.m.

When the plane landed at the airport, the passengers had not yet arrived. Passengers were brought to the airport in two buses with capacity for 50 people, with one seat distance between them. The windows of the buses were kept open to allow ventilation. After the passport procedures were completed, the passengers arrived at the airport at 05:30 a.m. They were then transferred from the waiting room to the plane by a bus carrying 75 people, making two trips. The windows of this bus were also kept open to allow ventilation. The bus parked 100 meters from the plane.

During the bus transfer, passengers wore normal surgical masks and did not wear protective clothing. One infection specialist and two nurses entered the bus and examined the passengers there. No pathology was detected in the examination of the passengers and vital signs were normal. A body temperature above $37^{\circ} \mathrm{C}$ was not detected in any passengers.

It was learned from the technical staff of the aircraft that the air flow would be from front to back and there was no negative pressure on the plane (Figure 1). It was therefore decided to board passengers from the rear cargo door of the plane. After the examinations on the bus were completed, the plane's rear cargo door was opened to the passengers. A total of 100 seats were placed on the plane. The seating plan consisted of 25 rows and 6 seats per row. One seat $(120 \mathrm{~cm})$ was left empty beside each passenger (Figure 1). Passengers were instructed by one paramedic and one nurse in a practical way about how to wear D-type protective clothing, glasses, gloves, and N95 masks. Each passenger was allowed onto the plane after putting on their personal protective suit and mask. Pilots, crew, and medical personnel were wearing D-type protective equipment, N95 masks, and glasses. The passengers, who would get off the plane first, were seated in the back of the plane. The aircraft crew and medical staff sat behind the passengers. Passengers were asked if they had any complaints and their body temperatures were measured at 1-hour intervals.

Passengers ate at different times on the plane. Starting from the first row, the passengers in each row ate at the same time. During the trip, passengers were allowed to take off their masks only while eating. Their masks were changed after each meal or when they went to the toilet. Hand washing and use of disinfectants were mandatory after eating or using the toilet. The plane landed at Ankara Etimesgut Military Airport at 9:20 p.m. A final

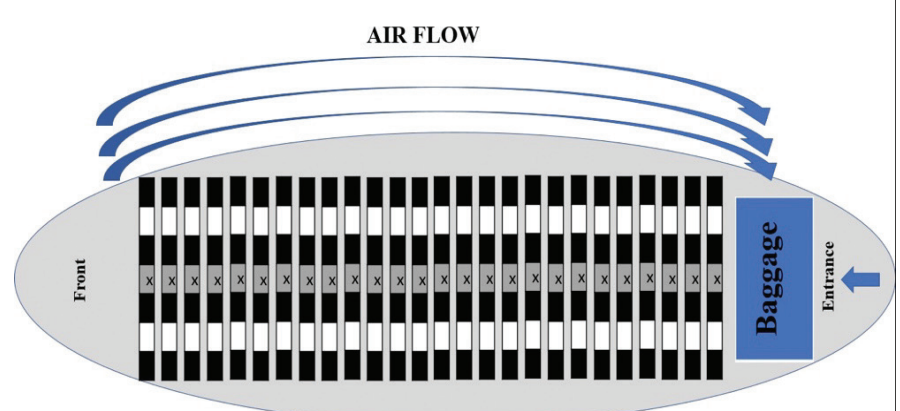

Figure 1. Seating arrangement of passengers and air flow in aircraft

Black seats: Seats for passengers, white seats: empty seats, x: corridor 
examination and body temperature control were performed before landing.

When the plane landed, ambulances were waiting 100 meters from the location where the plane would be parked. Ambulance personnel also wore D-type protective clothing, glasses, gloves, and $\mathrm{N} 95$ masks. After the plane was parked, patient transfer started from the rear cargo door. Each ambulance had a number and transported the passengers assigned to them. Ambulances were positioned 10 meters from the rear cargo door of the plane. Passengers were then taken off the plane one by one, taken to ambulances, and transported to the hospital (Figure 2).

When the ambulances arrived at the hospital, the hospital staff welcomed the passengers. Hospital personnel also wore D-type protective clothing, glasses, gloves, and N95 masks. Each passenger was taken to a room prepared for follow-up purposes. Each room was allocated for one passenger. Families were followed in rooms with a maximum of two people (mother and child).

The clothes of the ambulance team that completed the transfer were placed in medical waste bags and thrown into a medical waste bin. The ambulances were disinfected before they were assigned to any other cases. For sterilization, solutions containing $\mathrm{H}_{2} \mathrm{O}_{2}$ and $\mathrm{Ag}^{+}$were sprayed with a Dismist ${ }^{\circledR} \mathrm{S} 2$ device (Human Health Technology, 2019). After spraying the solution for 15 minutes for each ambulance, the solution was allowed to settle for 2 hours and 15 minutes. After this process was over, ambulances were ventilated with fresh air for 30 minutes.

The patients were followed in the hospital for 14 days. Nurses wore D-type protective clothing, gloves, glasses, and masks when entering the rooms. Vital findings were examined four times each day. Since there were no clear guidelines for COVID-19

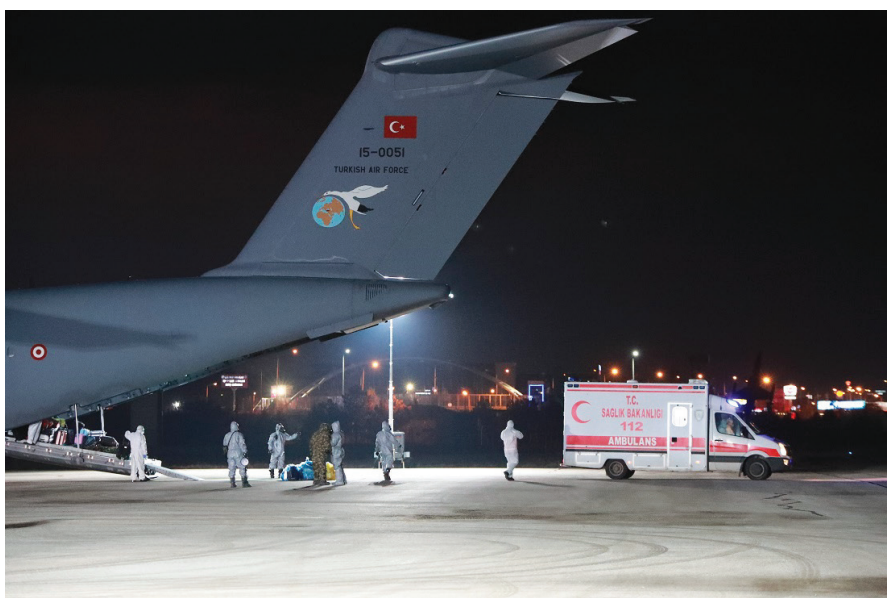

Figure 2. Transporting patients from plane to ambulance at the beginning of the pandemic, a commission of infection specialists was established within the Ankara Provincial Health Directorate during this period. Follow-up and treatment process decisions for the patients were made by this commission. Since this commission considered the passengers coming from abroad as high risk, they recommended taking swab samples from them every 3 days. Since this commission recommended that the patients be followed for 14 days, the quarantine period was determined as 14 days.

A nasal swab sample was taken from the passengers on the day of hospitalization and then every 3 days. The last nasal swab was performed on the day of discharge. The quarantine was terminated for the passengers who did not have coronavirus in swab samples and who did not develop disease findings and fever.

The Non-Invasive Ethics Committee of the University of Health Sciences approved our study with number 2020/93, date: 25.02.2020.

\section{Results}

A total of 42 people were transported from the city of Wuhan to Turkey. Among them, 27 were citizens of Turkey, six were citizens of Azerbaijan, four were dual citizens of China and Turkey, three were citizens of Georgia, one was a citizen of Bulgaria, and one was a citizen of Albania. While 22 of the transported individuals were male, 20 were female. The mean age was $30.1 \pm 10.6$ years.

The transported passengers did not have serious comorbidities. While one passenger had diabetes mellitus and hypothyroidism, one had rheumatoid arthritis, and another had diabetes mellitus and chronic gastritis.

The vital findings of the passengers were normal (Table 1).

\section{Discussion}

The rapid spread of COVID-19 is likely to be driven by the phenomenon of superspreading. Superspreading describes heightened transmission of a disease to at least eight contacts and has been observed for several infectious diseases including Severe acute respiratory syndrome, Middle East respiratory syndrome and influenza. Another reason for the rapid spread of COVID-19 is that modern air travel allows passengers to traverse the globe in less than a day (9). Thus, Turkey blocked all flights from China. However, a special transport flight was organized because Turks living in China wanted to return to Turkey.

Emergency medical services (EMS) play a vital role in responding to requests for assistance, triaging patients, and providing 
Table 1. The vital findings of the passengers

\begin{tabular}{|l|l|l|}
\hline & Mean \pm SD & Min-max \\
\hline Age & $30.2 \pm 12.1$ & $29.5(3.0-62.0)$ \\
\hline Systolic arterial pressure $(\mathbf{m m H g})$ & $125.2 \pm 15.5$ & $125.0(90.0-155.0)$ \\
\hline Diastolic arterial pressure $(\mathbf{m m H g})$ & $74.6 \pm 9.6$ & $75.0(60.0-95.0)$ \\
\hline Fever $\left({ }^{\circ} \mathbf{C}\right)$ & $36.5 \pm 0.3$ & $36.5(36.0-37.2)$ \\
\hline Pulse (min) & $78.9 \pm 12.6$ & $79.0(60.0-112.0)$ \\
\hline Sp0 $(\%)$ & $96.6 \pm 1.5$ & $96.0(95.0-99.0)$ \\
\hline SD: Standard deviation, min: Minimum, max: Maximum & & \\
\hline
\end{tabular}

emergency medical treatment and transport for ill persons. Unlike patient care in the controlled environment of a healthcare facility, care and transport by EMS present unique challenges because of the nature of the setting, enclosed space during transport, frequent need for rapid medical decision-making, interventions with limited information, and a varying range of patient acuity and jurisdictional healthcare resources (10). In this study, however, operational planning was performed in the early period, the personnel were informed, and necessary measures were taken.

According to the WHO, a patient with acute respiratory illness and a history of travel to a country that has reported local transmission of COVID-19, a patient with acute respiratory illness who has come into contact with a confirmed or probable case of COVID-19, or a patient with severe acute respiratory infection who requires hospitalization constitutes a suspected case of COVID-19 (11). The passengers transported from Wuhan to Turkey had no symptoms and did not meet this definition.

According to one study, the mean incubation period of 2019nCoV was 5.2 days [95\% confidence interval (Cl): 4.1-7.0] (12). In another study the mean incubation period was estimated to be 6.4 days ( $95 \% \mathrm{Cl}: 5.6-7.7)$ among travelers from Wuhan, China (13). Studies have reported that the disease is transmitted from humans to humans $(14,15)$. On the day of transport, there were still no COVID-19 cases in Turkey. The incubation period of the disease was reported to be 14 days in the guidelines of the Science Board of the Ministry of Health of Turkey, and the patients reported here were regularly screened for COVID-19, as it was recommended to take a throat swab sample every 3 days. In the literature, it appears that each country has its own guidelines. For example, after an operation to transport citizens home from Italy, South Korea applied quarantine for 14 days and administered throat swabs every 2 days (8).

In a study on the transport of patients with Lassa fever, it was stated that the transport of those patients was possible only with the correct use of necessary medical and technical equipment and personal protective equipment (16). Due to this information, no risks were taken and both aircraft personnel and ambulance crew used disposable examination gloves, disposable isolation gowns, N95 masks, and protective glasses according to the Centers for Disease Control and Prevention recommendations.

Since COVID-19 was suspected during a flight from Israel to Germany, two seats were left empty between passengers (17). The WHO recommends a distance of at least 1 meter for protection from COVID-19 transmission (18). In our organization, in accordance with the literature and the WHO recommendations, passengers were seated on the plane while leaving 1 seat (120 $\mathrm{cm}$ ) empty between them.

In a study describing the transport process of patients affected by a tsunami, it was emphasized that pre-operative organization was very important for the success of the transport (19). We also conducted detailed pre-operation planning in our study. Before the operation, all details such as the necessary equipment, how to use the equipment, the necessary meals and drinks for the passengers, the seating plan, the number of personnel to be sufficient according to the number of passengers, where the passengers would be quarantined, and the ambulances to be used for transport from the aircraft to the quarantine buildings were considered. In another study on the transport of COVID-19 patients, the seating plan was determined while considering even the airflow on the plane (17). In our planning, since the airflow on the plane was from front to back, the boarding of the passengers onto the plane and the seating plan were arranged accordingly.

\section{Conclusion}

In this paper, we have presented the details of the organization of a very successful large transfer of Turkish people from Wuhan back to Turkey. In epidemics and pandemics, taking the necessary precautions in the transport of passengers by plane during evacuations from risky areas is very important to prevent the spread of infectious diseases such as COVID-19. 


\section{Ethics}

Ethics Committee Approval: The Non-Invasive Ethics Committee of the University of Health Sciences approved our study with number 2020/93, date: 25.02.2020.

Informed Consent: Since this study does not contain the data of the patients, informed consent is not necessary.

Peer-review: Externally peer-reviewed.

\section{Authorship Contributions}

Design: I.S., B.B., Data Collection or Processing: E.U., Analysis or Interpretation: A.E.K., Literature Search: S.K., Writing: B.B.

Conflict of Interest: No conflict of interest was declared by the authors.

Financial Disclosure: The authors declared that this study received no financial support.

\section{References}

1. World Health Organization. Novel Coronavirus (2019-nCoV) - Situation report Available from: https://www.who.int/docs/default-source/coronaviruse/ situation-reports/20200121-sitrep-1-2019-ncov.pdf?sfvrsn=20a99c10_4 (Accessed Feb 16, 2020).

2. World Health Organization. Statement on the second meeting of the International Health Regulations (2005) Emergency Committee regarding the outbreak of novel coronavirus (2019-nCoV). Geneva: the Organization; 2020 Available from: https://www.who.int/news-room/detail/30-01-2020statement-on-the-second-meeting-of-the-international-health-regulations(2005)-emergency-committee-regarding-the-outbreak-of-novel-coronavirus(2019-ncov) (Accessed Feb 16, 2020)

3. World Health Organization. Novel Coronavirus (2019-nCoV) - Situation report -22, Available from: https://www.who.int/docs/default-source/coronaviruse/ situation-reports/20200211-sitrep-22-ncov.pdf?sfvrsn=fb6d49b1_2 (Accessed Feb 16, 2020)

4. World Health Organization. Novel Coronavirus (COVID-19) Situation. Available from: https://experience.arcgis.com/experience/685d0ace521648f8a5beeeee 1b9125cd (Accessed 16 Mar, 2020).

5. Wood C. Infections without borders: a new coronavirus in Wuhan, China. $\mathrm{Br}$ J Nurs. 2020;29. doi: 10.12968/bjon.2020.29.3.166

6. National Health Commission of the People's republic of China. Latest on the novel coronavirus outbreak. 20.01.2020 Available from: http://en.nhc.gov. cn/2020-01/29/c_76043.htm (Accessed 17.02.2020).
7. Centers for Disease Control and Prevention. Travelers from China Arriving in the United States. https://www.cdc.gov/coronavirus/2019-ncov/travelers/ from-china.html (Accessed Feb 17, 2020).

8. Albrecht R, Knapp J, Theiler L, Eder M, Pietsch U. Transport of COVID-19 and other highly contagious patients by helicopter and fixed-wing air ambulance: a narrative review and experience of the Swiss air rescue Rega. Scand J Trauma Resusc Emerg Med. 2020;28:40.

9. Lee A. Wuhan novel coronavirus (COVID-19): why global control is challenging? Public Health. 2020;179:A1-A2.

10. Centers for Disease Control and Prevention. Interim Guidance for Emergency Medical Services (EMS) Systems and 911 Public Safety Answering Points (PSAPs) for COVID-19 in the United States. Available from: https://www.cdc. gov/coronavirus/2019-ncov/hcp/guidance-for-ems.html (Accessed 24 Feb, 2020).

11. World Health Organization. Global Surveillance for COVID-19 disease caused by human infection with novel coronavirus (COVID-19), Interim Guidance. Available from: https://www.who.int/publications-detail/global-surveillancefor-human-infection-with-novel-coronavirus-(2019-ncov) (Accessed 01 Mar, 2020).

12. Li Q, Guan X, Wu P, Wang X, Zhou L, Tong Y, et al. Early Transmission Dynamics in Wuhan, China, of Novel Coronavirus-Infected Pneumonia. N Engl J Med. doi: 10.1056/NEJMoa2001316

13. Backer JA, Klinkenberg D, Wallinga J. Incubation period of 2019 novel coronavirus (2019-nCoV) infections among travellers from Wuhan, China, 2028 January 2020. Euro Surveill. 2020;25:2000062.

14. Chan JF, Yuan S, Kok KH, To KK, Chu H, Yang J, et al. A familial cluster of pneumonia associated with the 2019 novel coronavirus indicating personto-person transmission: a study of a family cluster. Lancet. 2020;395:514-23.

15. Huang C, Wang Y, Li X, Ren L, Zhao J, Hu Y, et al. Clinical features of patients infected with 2019 novel coronavirus in Wuhan, China. Lancet. 2020;395:497506.

16. Lotz E, Raffin H. Aeromedical evacuation using an aircraft transit isolator of a patient with Lassa fever. Aviat Space Environ Med. 2012;83:527-30.

17. Hoehl S, Karaca O, Kohmer N, Westhaus S, Graf J, Goetsch U, et al. Assessment of SARS-CoV-2 Transmission on an International Flight and Among a Tourist Group. JAMA Netw Open. 2020;3:e2018044.

18. World Health Organization. Coronavirus disease (COVID-19) advice for the public. Available from: https://www.who.int/emergencies/diseases/novelcoronavirus-2019/advice-for-public (Accessed 25 Aug, 2020).

19. Björnsson HM, Kristjánsson M, Möller AD. Converted charter plane for mass transport of patients after a tsunami. Air Med J. 2008;27:293-8. 